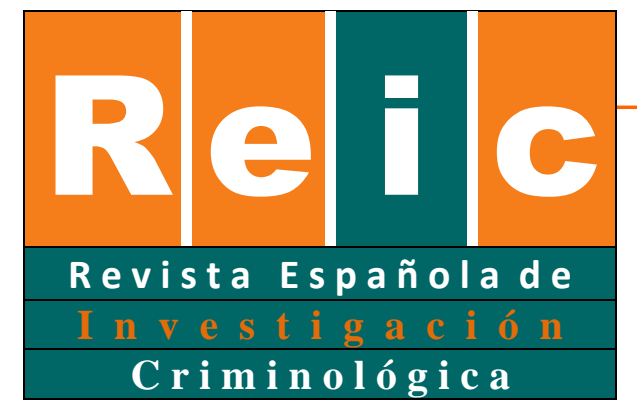

Bobbio, Arbach \& Redondo

\title{
El Modelo del Triple Riesgo Delictivo en la explicación de la conducta antisocial de adolescentes varones y mujeres
}

\section{The Triple Risk for Crime and Delinquency Model in the explanation of antisocial behavior of male and female adolescents}

Recibido el 21 enero 2021/ Aceptado 29 septiembre 2021

Antonella Bobbio iD 1

Universidad Nacional de Córdoba, Argentina

Consejo Nacional de Investigaciones Científicas y Tecnológicas, Instituto de Investigaciones Psicológicas de Córdoba, Argentina

Karin Arbach

Universidad Nacional de Córdoba, Argentina

Consejo Nacional de Investigaciones Científicas y Tecnológicas, Instituto de Investigaciones Psicológicas de Córdoba, Argentina

Santiago Redondo

iD

Universidad de Barcelona

\footnotetext{
${ }^{1}$ La correspondencia debe dirigirse a: Antonella Bobbio, Facultad de Psicología, Universidad Nacional de Córdoba, Argentina. Enfermera Gordillo esq. Enrique Barrios, Ciudad Universitaria, Instituto de Investigaciones Psicológicas, Córdoba (5000), Argentina; E-mail: antonellabobbio@ hotmail.com.
}

Revista Española de Investigación Criminológica

Artículo 6, Volumen 19 (2021)

https://doi.org/10.46381/reic.v19i1.479

Www.criminologia.net

ISSN: 1696-9219 


\title{
RESUMEN
}

En este estudio se evalúan la conducta antisocial y los principales factores de riesgo presentes en una muestra de 428 adolescentes argentinos de la provincia de Córdoba, tanto varones como mujeres. Para ello se toma como base el Modelo del Triple Riesgo Delictivo (TRD) (Redondo, 2008, 2015), que sugiere la existencia de tres fuentes criminógenas principales que operan en interacción: riesgos personales, carencias sociales y exposición a oportunidades delictivas. Los resultados obtenidos confirman, en primer lugar, que los varones tienen una participación delictiva muy superior a la de las chicas; en segundo, que existen diversas similitudes a la vez que también algunas diferencias entre mujeres y varones, por lo que se refiere a la influencia y capacidad predictiva de los diversos factores de riesgo aquí analizados. En concreto, aunque algunos de los factores de riesgo incluidos en el estudio (p. e. pares antisociales, consumo de sustancias y pobre parentalidad) fueron útiles para explicar el comportamiento antisocial tanto de varones como chicas, la magnitud de varianza explicada por ellos fue superior para el caso de los varones. Los hallazgos del estudio apoyan empíricamente algunas de las propuestas del Modelo TRD, a la vez que sugieren que las evaluaciones e intervenciones sobre el comportamiento antisocial y sus factores de riesgo deberían tomar en cuenta las diferencias por sexo.

Palabras clave: Modelo del Triple Riesgo Delictivo (TRD); adolescentes; motivación delictiva; sexo; delincuencia femenina.

\begin{abstract}
This study evaluates the antisocial behavior and its main risk factors in a sample of 428 Argentine adolescents from the province of Córdoba, both men and women. For this, the Triple Risk for Crime and Delinquency Model (TRD) (Redondo, 2008, 2015) is taken as a basis. The TRD model suggests the relevance of three main criminogenic sources which operate in interaction: personal risks, lack of social support and exposure to criminal opportunities. The results obtained confirm, firstly, that boys have a higher criminal involvement than girls; secondly, the existence of various similarities as well as some differences, between women and men, with regard to the influence and predictive capacity of the various risk factors evaluated. Specifically, although some of the risk factors included (eg, antisocial peers, substance use, and poor parental practices) were useful to explain antisocial behavior in both boys and girls, the magnitude of variance explained by them was higher for boys. The study findings empirically support some of the TRD Model proposals. They also suggest that assessments and interventions on antisocial behavior and its risk factors have to take into account the sex differences.
\end{abstract}

Keywords: Triple Risk for Crime and Delinquency Model (TRD); adolescents; criminal motivation; biological sex; female crime.

Revista Española de Investigación Criminológica

Artículo 6, Volumen 19 (2021)

https://doi.org/10.46381/reic.v19i1.479

Www.criminologia.net

ISSN: 1696-9219 


\section{Introducción}

Los estudios que analizan las diferencias en conducta delictiva entre varones y mujeres han evidenciado de manera consistente que el sexo es uno de sus predictores más robustos, mostrando en general los varones una mayor tendencia a involucrarse en un mayor número de delitos y de mayor gravedad (Liu \& Miller, 2020). Según cifras oficiales de diferentes países, alrededor del $60 \%$ de los delitos contra la propiedad y de los delitos de tráfico de drogas son cometidos por varones. Estas cifras ascenderían hasta el $90 \%$ cuando se trata de los delitos más violentos, como homicidios, robos con violencia, lesiones o delitos sexuales (Cortoni et al., 2010; Redondo, 2015). En la provincia de Córdoba (Argentina), donde se desarrolla el presente estudio, el $91 \%$ de los adolescentes institucionalizados anualmente por cometer delitos son varones (Centro de Estudios y Proyectos Judiciales, 2017). En paralelo a los datos oficiales, también los estudios de autoinforme muestran una clara mayor participación de los varones en la delincuencia y una menor presencia de las mujeres (Fernández-Molina \& Bartolomé Gutiérrez, 2020). Por ejemplo, en un estudio con 800 estudiantes universitarios en Argentina, las mujeres presentaron una prevalencia en conductas hetero-agresivas y hurtos entre 2 y 3 veces menor que la de los varones (Arbach, 2016).

Las diferencias observadas entre mujeres y hombres en la magnitud del comportamiento delictivo han suscitado un interés sostenido por analizar los factores que podrían explicar tales diferencias (Burt et al., 2019). No obstante, los resultados de los estudios realizados a este respecto no han sido unánimes, sino fuente de constantes controversias. Algunos investigadores han considerado que las diferencias entre ambos grupos serían esencialmente cuantitativas, por lo que se refiere tanto a la prevalencia y frecuencia de la conducta delictiva como a la magnitud de los riesgos que influyen en uno y otro sexo; pero que no existirían diferencias cualitativas en los mecanismos explicativos del delito (Cutrín et al., 2017; Javdani et al., 2011; Slawinski et al., 2019; Trudeau et al., 2012; Weerman \& Hoeve, 2012). Otros expertos han sugerido, por el contrario, que los factores y mecanismos explicativos del comportamiento delictivo podrían diferir, al menos 
parcialmente, entre chicas y chicos (Javdani \& Allen, 2014). Así podría ser por lo que se refiere a determinadas variables biológicas (p. e., la preeminencia de testosterona en los varones y el más temprano desarrollo puberal de las chicas), algunos factores de personalidad (p. e., impulsividad, búsqueda de sensaciones), o bien ciertos elementos cognitivos (p. e., distorsiones, justificaciones), experienciales y conductuales (Eme, 2018). Por ejemplo, distintos estudios han documentado que las mujeres que cometen delitos suelen haber experimentado, en contraste con los varones, una mayor victimización sexual infantil, una frecuente vinculación a parejas de mayor edad y una superior prevalencia de trastornos mentales como depresión o ansiedad (Chesney-Lind \& Shelden, 2014; Javdani et al., 2011; Kerig, 2018; Zahn et al., 2010).

Las diferencias en conducta delictiva entre varones y mujeres y sus posibles razones también se han considerado en la formulación de algunas teorías criminológicas recientes, como es el caso del Modelo del Triple Riesgo Delictivo (TRD; Redondo, 2008, 2015). La premisa central del Modelo TRD es que la influencia interactiva y continuada sobre un individuo de Riesgos personales (impulsividad, bajo autocontrol, creencias antisociales...) y Carencias en apoyo prosocial (familiar, escolar, económico, social) podría aumentar, en primer lugar, su motivación delictiva; a continuación, esta motivación antisocial incrementada, al interaccionar con la eventual exposición del sujeto a oportunidades delictivas, favorecería su mayor riesgo global de conducta infractora. La existencia de una mayor implicación delictiva de los varones, en contraste con una menor de las chicas, se considera el resultado de una incrementada convergencia y potenciación en los varones de riesgos de las tres fuentes aludidas (Redondo, 2015).

En lo relativo a los Riesgos personales, los varones presentarían, como la investigación general ha evidenciado, algunas características psicobiológicas diferenciadas, como un mayor nivel de testosterona (que se asocia a mayor reactividad y agresividad frente al estrés ambiental y los conflictos; LeDoux, 1999; Tobeña, 2003) y mayores niveles de extraversión e impulsividad (Gudjonsson et al., 2006; Mak et al., 2003). Al respecto de las Carencias en apoyo prosocial (familiar, escolar, social), muchos jóvenes varones podrían experimentar una socialización menos imbuida de responsabilización personal, vinculación

Revista Española de Investigación Criminológica

Artículo 6, Volumen 19 (2021)

https://doi.org/10.46381/reic.v19i1.479

www.criminologia.net

ISSN: 1696-9219 
emocional y control que las chicas (particularmente, en el marco de las familias), lo que podría asociarse a un mayor riesgo delictivo (Giddens, 2009; Redondo, 2015). Finalmente, los varones podrían verse más expuestos a determinadas Oportunidades infractoras, en la medida en que tenderían a efectuar un mayor número de desplazamientos y a pasar más tiempo en la calle, lo que podría asociarse a una menor supervisión adulta de su conducta (Weerman \& Hoeve, 2012). Así, según el Modelo TRD, la mayor proclividad delictiva de los varones resultaría de una confluencia incrementada en ellos de las tres principales influencias delictivas aducidas por esta teoría: riesgos personales, carencias prosociales y oportunidades infractoras (Redondo, 2015).

Dado el carácter relativamente novel y la complejidad estructural del Modelo TRD, no son muchos los estudios que han evaluado esta teoría o algunos de sus planteamientos. Aun así, tomando el Modelo TRD como base, se han analizado problemáticas delictivas y de justicia relativas a delincuencia juvenil, seguridad vial, delitos sexuales, ciberbullying y gestión penitenciaria (Direcció General d'Infància Joventut i Famílies, 2020a, 2020b, 2020c; Direcció General de Serveis Penitenciaris, 2011; El País, 2011). Entre estos análisis, Martín et al. (2015) evaluaron en Málaga una muestra de 422 estudiantes de secundaria, chicos y chicas, en el rango de edad 12-15 años, mediante el Inventario de Riesgos Individuales y Sociales (IRIS; Redondo, 2010; Redondo \& Martínez, 2014). En este estudio, el predictor Riesgo personal explicó el $20 \%$ de la varianza de la conducta antisocial, la Carencia en apoyo prosocial, un 25\%, y las Oportunidades delictivas, un 35\% (siendo esta misma la magnitud de la varianza explicada por el combinado de estas tres fuentes de riesgo).

Pérez Ramírez (2012) contrastó a gran escala la estructura teórica del Modelo TRD, evaluando empíricamente, mediante ecuaciones estructurales, los constructos motivación delictiva y riesgo de conducta antisocial. Para ello, seleccionó una muestra de 5.815 adolescentes varones, correspondientes al British Cohort Study de las universidades de Londres y Bristol. A partir de los datos disponibles en dicho estudio, se definieron 40 variables predictoras (17 de Riesgo personal, 17 Carencias en apoyo prosocial, y 6 relativas a Oportunidad delictiva) y 12 variables de conducta antisocial, incluida una medida global. Los resultados obtenidos en esta investigación confirmaron en gran medida la estructura

Revista Española de Investigación Criminológica

Artículo 6, Volumen 19 (2021)

https://doi.org/10.46381/reic.v19i1.479

www.criminologia.net

ISSN: 1696-9219 
conceptual del Modelo TRD, lográndose una explicación del 35\% de la varianza de la Motivación delictiva y un $40 \%$ de la varianza de la conducta antisocial. Sobresalió el influjo preeminente y directo de las Carencias en apoyo prosocial, tanto sobre la magnitud de la motivación antisocial como sobre el riesgo delictivo global. Además, las Carencias prosociales también modularon la influencia que los Riesgos personales y las Oportunidades tenían sobre el riesgo delictivo conjunto (Pérez Ramírez, 2012). Este estudio se realizó exclusivamente a partir de jóvenes varones, lo que no permitió delimitar si las influencias identificadas serían las mismas para el caso de las mujeres.

Posteriormente, González García (2015; González García \& Campoy Torrente, 2018) analizó algunas de las premisas del Modelo TRD en el contexto de la problemática del ciberbullying o acoso juvenil a través de Internet (mediante conductas como el envío a otros de comentarios o rumores injuriosos, de imágenes humillantes, vídeos comprometedores, etc.). Para ello seleccionó al azar una muestra de 297 estudiantes de educación secundaria en la provincia de Madrid, en un 51,5\% varones y en un 48,5\% chicas, con una edad media de 14,42 años. La evaluación de los jóvenes se efectuó a partir de un cuestionario creado al efecto que, entre otros aspectos, permitía definir 4 factores de Riesgo personal (impulsividad, autoestima...), 7 Carencias en apoyo prosocial (apoyo de los padres, profesores, supervisión en Internet...) y 4 factores de Oportunidad (clima escolar, precipitadores situacionales -p. e., reactividad frente a una agresión previamente sufrida, anonimato, frecuencia de uso de Internet, etc.). Pudo establecerse que los mejores predictores personales eran la baja autoestima y la alta impulsividad, el predictor más sólido de carencias sociales, la falta de apoyo de los profesores, y el mejor predictor de oportunidad, la presencia de precipitadores situacionales (anonimato, frecuencia de uso de internet...). La combinación o convergencia de los factores alta impulsividad (riesgo personal) y precipitadores situacionales (oportunidad delictiva) explicó el 30\% de la varianza del ciberbullying, y permitió clasificar correctamente al 97,4\% de los jóvenes acosadores. Por lo que se refiere a la variable sexo, se efectuó una comparación entre las conductas de ciberbullying emitidas por los varones y las chicas, sin hallar en este caso diferencias relevantes entre ambos grupos. Pese a todo, no constituyó un

Revista Española de Investigación Criminológica

Artículo 6, Volumen 19 (2021)

https://doi.org/10.46381/reic.v19i1.479

www.criminologia.net

ISSN: 1696-9219 
objetivo de este estudio el análisis diferencial del Modelo TRD según el sexo de los participantes.

\subsection{El presente estudio}

Aunque algunos de los estudios mencionados han considerado la posible variabilidad de la conducta delictiva en función del sexo, en general tanto la evaluación como el tratamiento de las mujeres que cometen delitos han sido ámbitos bastante desatendidos (Loinaz, 2016), particularmente en Latinoamérica (Vizcaíno Gutiérrez, 2010). Esto podría deberse a factores como la escasa representación de las mujeres en el conjunto de la delincuencia y la consiguiente menor preocupación por ellas, las frecuentes dificultades de acceso a muestras delictivas femeninas (como así sucedió en este estudio), o las vigentes consideraciones sociales, políticas, e incluso epistemológicas, que atribuirían a las mujeres un rol casi exclusivo de víctimas y no de posibles agresoras (Echeburúa \& Redondo, 2010).

En Argentina anualmente se registran más de 7.000 casos de adolescentes y jóvenes adultos en conflicto con la ley penal, de los cuales una minoría, aproximadamente un 6\%, son mujeres (UNICEF \& SeNAF, 2015). En Latinoamérica en su conjunto son escasos los estudios empíricos sobre conducta delictiva y todavía son menos los que evalúan diferencias entre varones y mujeres. Pese a ello, en una investigación desarrollada en Venezuela se analizó una muestra de 471 adolescentes escolarizados; se halló que la inadecuada supervisión familiar, la vinculación con amigos antisociales y el bajo nivel de autocontrol eran los tres factores más asociados a la conducta desviada de los adolescentes de ambos sexos, aunque en mayor grado a la de los varones (Rodríguez et al., 2012). Un estudio de autoinforme con jóvenes universitarios en Argentina también evidenció que los varones presentaban tasas de conducta delictiva más elevadas que las chicas, con prevalencias entre 2 y 3 veces superiores en conductas heteroagresivas y hurtos (Arbach, 2016). Sin embargo, no se han localizado estudios desarrollados en Argentina que ponderen las posibles diferencias existentes en los factores explicativos de la conducta antisocial de adolescentes varones y mujeres. Pese a ello, tales diferencias deberían explorarse convenientemente, con

Revista Española de Investigación Criminológica

Artículo 6, Volumen 19 (2021)

https://doi.org/10.46381/reic.v19i1.479

Www.criminologia.net

ISSN: 1696-9219 
el objetivo final de generar estrategias de prevención y tratamiento más específicas y acordes con las necesidades principales de cada sexo.

\section{Objetivos}

Sobre la base de lo comentado, el objetivo general de este estudio es contrastar empíricamente la estructura teórica del Modelo TRD en adolescentes varones y mujeres, mediante los dos siguientes objetivos específicos: a) analizar la influencia diferencial de distintos factores de riesgo en jóvenes de ambos sexos; b) a partir de ello, estimar el poder explicativo sobre la conducta delictiva mostrado por el Modelo TRD en cada grupo.

\section{Metodología}

\subsection{Participantes}

Con las finalidades mencionadas se evaluó una muestra accidental no probabilística, compuesta inicialmente por 494 adolescentes de 13 a 20 años $(M=15.82 ; D S=1.56)$ de la provincia de Córdoba, Argentina. Aproximadamente, el 18\% de los participantes $(n=89)$ eran residentes, en el momento de la evaluación, en un centro de internamiento cerrado para adolescentes en conflicto con la ley penal; todos ellos varones, dado que no se tuvo acceso a la institución que alojaba a las chicas privadas de libertad. El resto de los participantes eran estudiantes de ambos sexos de cuatro institutos de educación media de la provincia de Córdoba. Tras la inspección de valores perdidos, se eliminaron de la muestra 66 sujetos que habían dejado en blanco más del 10\% de alguna de las escalas de evaluación administradas. Así, la muestra final quedó conformada por 428 adolescentes, de los cuales un $48 \%$ eran mujeres. Alrededor del 50\% del conjunto de los participantes reportó que tanto su padre como su madre tenían estudios secundarios o superiores, a la vez que un $43 \%$ manifestó convivir con ambos progenitores.

Revista Española de Investigación Criminológica

Artículo 6, Volumen 19 (2021)

https://doi.org/10.46381/reic.v19i1.479

www.criminologia.net

ISSN: 1696-9219 


\subsection{Procedimiento}

Tras obtener las correspondientes autorizaciones institucionales de los centros donde se encontraban los adolescentes (institutos educativos o centros de internamiento), se procedió a la recogida de los datos. Previamente se solicitó a todos los participantes su consentimiento informado, de acuerdo con las normas éticas de la investigación psicológica (Ethical principles of psychologists and code of conduct, 2017), la legislación argentina de protección de datos personales (Ley 25326, 2000) y los requerimientos de cada institución. En el documento de consentimiento se recogían con claridad los objetivos del estudio, sus implicaciones y el carácter voluntario de la participación en el mismo, así como la plena confidencialidad en el tratamiento de los datos. En el centro cerrado para menores infractores, la recogida de datos se llevó a cabo de manera colectiva, en grupos de 2 a 5 participantes, en lugares dispuestos por la institución para tal fin. En el caso de los centros educativos, los instrumentos se administraron en las aulas o en espacios análogos, de manera colectiva y con la presencia de un docente y de la investigadora responsable del estudio.

\subsection{Variables e instrumentos}

\section{Variables independientes de riesgos personales}

Bajo autocontrol. Para la evaluación de esta variable se administró la Escala de Bajo Autocontrol (Grasmick et al., 1993) adaptada al español (Bobbio \& Arbach, 2020). Se trata de una escala de autoinforme compuesta por 24 ítems, que evalúan características de las personas con bajo autocontrol como impulsividad, preferencia por tareas fáciles y actividades físicas, egocentrismo, búsqueda de riesgos y temperamento volátil. Las respuestas pueden oscilar en una escala Likert de cinco puntos, desde totalmente falso (0) a totalmente cierto (4). Este instrumento evidenció un índice de confiabilidad bueno $(\alpha=.86)$.

Consumo problemático de drogas. El consumo de sustancias se evaluó a partir de la subescala de uso de drogas (ocho ítems) de la versión adaptada al español (Garrido et al., 2019) de la Normative Deviance Scale (Vazsonyi et al., 2001). El ítem “ ¿Fuiste a trabajar borracho o drogado?" no fue incluido finalmente en los análisis realizados, debido al alto porcentaje de datos perdidos que presentó (85\%). Ello probablemente fue debido a que el

Revista Española de Investigación Criminológica

Artículo 6, Volumen 19 (2021)

https://doi.org/10.46381/reic.v19i1.479

www.criminologia.net

ISSN: 1696-9219 
contenido de dicho ítem se refiere al ámbito laboral y muchos de los adolescentes de la muestra aún no tenían ninguna experiencia laboral. Las respuestas a esta escala se presentaron en una dimensionalidad tipo Likert de cinco puntos, desde nunca lo hice (0) a lo hice seis veces o más (4). La escala mostró un muy buen índice de confiabilidad $(\alpha=.90)$.

\section{Variables independientes de carencias prosociales}

Pobre parentalidad materna. Las prácticas parentales fueron valoradas a través de la versión en español (Bobbio et al., 2016) de la Adolescent Family Process Measure (Vazsonyi et al., 2003). Este instrumento se compone de seis subescalas: cercanía, apoyo, monitoreo o supervisión, comunicación, conflicto y aprobación del grupo de pares. Se responde a él en una escala tipo Likert de cinco puntos, desde totalmente falso (0) a totalmente cierto (4). Los ítems de cercanía, monitoreo, comunicación y aprobación de pares fueron recodificados a la inversa, de manera que las puntuaciones reflejaran las prácticas parentales en un sentido negativo, es decir como un factor de riesgo (a mayor puntaje, más prácticas parentales inadecuadas). Todas las subescalas mostraron buen índice de confiabilidad en la muestra ( $\alpha$ $=.66 \mathrm{a} .82)$.

Pares antisociales. La asociación con compañeros antisociales se evaluó preguntando a los participantes cuántos amigos en su grupo realizaban los siguientes comportamientos: fumar marihuana, beber alcohol habitualmente, destruir cosas en lugares públicos, romper cosas de otras personas, consumir drogas de forma ilegal (cocaína, pastillas, paco ${ }^{2}$, etc.), amenazar o atacar a otras personas, discutir violentamente con sus padres o maestros, o robar. Las opciones de respuesta se estructuraban en una escala Likert de tres categorías, desde ninguno de mis amigos lo hace (0) hasta la mayoría de mis amigos lo hacen (2). La variable mostró un buen índice de confiabilidad $(\alpha=.82)$.

\section{Variable independiente de oportunidad}

Oportunidad delictiva. Se evaluó de manera indirecta, a través de cuatro preguntas diseñadas ad hoc para medir la percepción que los jóvenes tenían acerca de los posibles problemas y disturbios existentes en su barrio. En concreto, se les interrogó sobre el grado

\footnotetext{
${ }^{2}$ Droga de bajo coste en Argentina, similar al crack, fabricada a base de sulfato de cocaína y procesada con ácido sulfúrico y queroseno.
}

Revista Española de Investigación Criminológica

Artículo 6, Volumen 19 (2021)

https://doi.org/10.46381/reic.v19i1.479

www.criminologia.net

ISSN: 1696-9219 
en que había vandalismo, casas abandonadas, robos y agresiones entre los vecinos. Las opciones de respuesta consistieron en una escala tipo Likert de tres categorías, que podían oscilar desde esto nunca pasa en mi barrio (0) a esto pasa con frecuencia en mi barrio (2). La variable mostró un índice de confiabilidad bueno $(\alpha=.77)$.

Motivación delictiva. La motivación delictiva (MD) se estimó a partir de multiplicar las puntuaciones de los sujetos en las diversas variables de riesgo personales y de carencia prosocial (bajo autocontrol * consumo problemático de sustancias * prácticas parentales * pares antisociales). Se procedió de este modo siguiendo la definición de motivación delictiva del Modelo TRD según el cual la MD sería producto de la interacción entre factores de riesgo personales y carencias prosociales. Para reducir la amplitud y consiguiente complejidad del rango de puntuaciones directas resultantes en cada variable, los puntajes directos se transformaron a una escala de 1 a 4 puntos. Para ello se dividió el rango posible de respuestas en cada variable en cuatro intervalos. De esta manera, las puntuaciones finales en motivación delictiva se situaron, como resultado de los productos correspondientes, en un rango total de 0 a 256 puntos.

\section{Variable dependiente}

Conducta antisocial. Se valoró la conducta antisocial de los jóvenes a partir de las subescalas de Vandalismo, Hurto y Agresiones físicas de la NDS (Garrido et al., 2019; Vazsonyi et al., 2001), que se componen de 7, 5 y 6 ítems, respectivamente. Se responden en una dimensionalidad tipo Likert de cinco puntos desde nunca lo hice (0) a lo hice seis veces o más (4). Las tres subescalas evidenciaron índices de confiabilidad entre moderados y buenos $(\alpha=.65-.78)$. Los puntajes directos de los sujetos en cada ítem (dados por las frecuencias en que habían cometido cada comportamiento) fueron ponderados por tres jueces independientes en función de la gravedad de las diversas conductas. De este modo, se calculó una variable continua, denominada conducta antisocial, sumando las puntuaciones ponderadas de cada ítem. El rango posible en esta variable osciló entre 0 y 188. 


\subsection{Análisis de datos}

En primer lugar, se llevaron a cabo análisis descriptivos de todas las variables en estudio, tanto en relación con la muestra global como separadamente para varones y mujeres. Se evaluaron los supuestos de normalidad, para analizar la calidad de la base de datos, mediante el paquete estadístico SPSS versión 22 (IBM Corp., 2013).

Posteriormente, se especificó y se estimó el Modelo TRD mediante la técnica de Modelos de Ecuaciones Estructurales (SEM), utilizando para ello el método de estimación de Máxima Verosimilitud (ML), a través del programa AMOS versión 21 (IBM Corp., 2012). De inicio, se especificó un modelo de estructura (figura 1) que incluyó cuatro variables exógenas (independientes, es decir que no reciben influencia de ninguna otra variable del modelo). Dos de ellas pertenecían a la fuente de riesgos personales (bajo autocontrol y consumo de drogas) y otras dos, a la fuente de carencias prosociales (pobre parentalidad materna y pares antisociales). Se establecieron covarianzas entre estas cuatro variables, de acuerdo al principio de convergencia de riesgos intra e inter-fuentes propuesto por el Modelo TRD, que asume que diversos riesgos personales, carencias prosociales y oportunidades delictivas propenderán a converger relativamente en el mismo individuo. Según esta propuesta teórica, las variables que representan los riesgos personales y sociales influirían directamente sobre la motivación delictiva (variable mediadora), la cual a su vez ejercería y recibiría una influencia directa de la oportunidad delictiva, de acuerdo al principio de interdependencia. Finalmente, la oportunidad y la motivación delictiva serían predictores directos de la conducta antisocial (Figura 1). 


\section{Figura 1.}

Modelo especificado del Triple Riesgo Delictivo

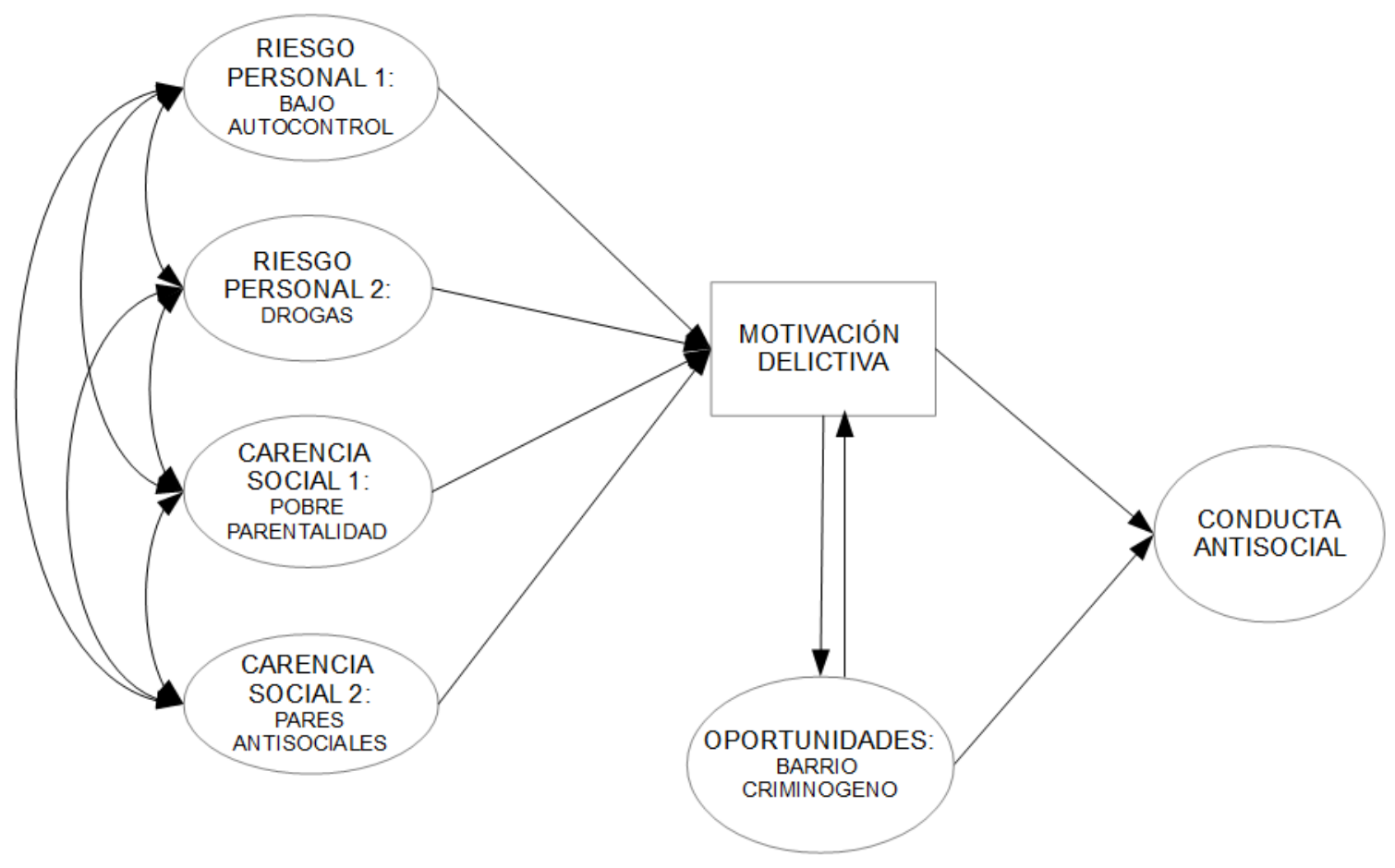

Nota. La figura no incluye las parcelas y sus términos de error.

Los indicadores de las variables latentes del estudio fueron incorporados al modelo en forma de parcelas que se conformaron mediante la distribución de ítems con cargas factoriales equivalentes. Es decir, los ítems se agruparon de tal forma que las sumas de sus cargas factoriales fueran equivalentes entre las diferentes parcelas de una variable. También se controló que cada parcela tuviera representación de ítems de todas las subescalas utilizadas.

Luego se puso a prueba un modelo de medida y se procedió a efectuar el análisis multigrupo entre varones y mujeres. Para ello se propuso un modelo sin restricciones (Modelo Libre o ML) donde se permitió que todos los parámetros fueran libres, es decir que pudiesen variar según la muestra de cada sexo. En un segundo momento, se estableció un modelo con restricciones en los coeficientes path (Modelo de Invarianza 1 o MI1), 
determinando que eran iguales para ambos grupos. Posteriormente, se formuló un modelo con restricciones en las covarianzas entre los predictores (Modelo de Invarianza 2 o MI2). Por último, se estimó un modelo con restricciones en los residuales de las variables endógenas (Modelo de Invarianza 3 o MI3). Para evaluar el ajuste de estos cuatro modelos se utilizaron los siguientes indicadores: el estadístico chi cuadrado $\left(\chi^{2}\right)$, chi cuadrado sobre los grados de libertad $\left(\chi^{2} / g l\right)$, el Índice de Ajuste Comparativo (CFI), el Índice de Bondad del Ajuste (GFI), el Error Cuadrático Medio de Aproximación (RMSEA) y el Residuo Cuadrático Medio Estandarizado (SRMR). Se esperaba que la relación de chi-cuadrado sobre los grados de libertad arrojara índices por debajo de 3.0 (Kline, 2011). Para los índices CFI y GFI, los valores entre .90 y .95 se consideraron como indicadores de un ajuste aceptable y los superiores a .95 representativos de un ajuste excelente. Para el RMSEA y el SRMSR, se esperaban valores por debajo de .08 (Hair et al., 2006).

\section{Resultados}

\subsection{Análisis descriptivos}

En la tabla 1 se reportan los análisis descriptivos de las variables (media, desviación típica, asimetría y curtosis) para la muestra total y diferenciada por sexo.

Revista Española de Investigación Criminológica 


\section{Tabla 1}

Estadísticos descriptivos de las variables en estudio

\begin{tabular}{|c|c|c|c|c|c|c|}
\hline & \multicolumn{3}{|c|}{ Muestra total } & \multirow{2}{*}{$\begin{array}{l}\text { Mujeres } \\
M(D T)\end{array}$} & \multirow{2}{*}{$\begin{array}{l}\text { Varones } \\
M(D T)\end{array}$} & \multirow[t]{2}{*}{ Prueba $t$} \\
\hline & $M(D T)$ & Asimetría & Curtosis & & & \\
\hline 1.Bajo autocontrol & $45.55(13.19)$ & -0.1 & 0.41 & $43.23(12.44)$ & $47.87(13.53)$ & $* * *$ \\
\hline 2.Consumo de drogas & $5.65(7.86)$ & 1.45 & 1.05 & $2.77(5.1)$ & $8.32(9.07)$ & $* * *$ \\
\hline 3.Pobre parentalidad & $34.30(15.47)$ & 0.37 & 0.09 & $33.03(16.9)$ & $35.60(13.88)$ & ns \\
\hline 4.Pares antisociales & $4.86(3.48)$ & 0.77 & 0.15 & $4.11(3.23)$ & $5.51(3.65)$ & $* * *$ \\
\hline 5.Oportunidad delictiva & $3.12(2.32)$ & 0.44 & -0.8 & $2.94(2.17)$ & $3.32(2.47)$ & $n s$ \\
\hline 6.Motivación delictiva & $14.74(21.21)$ & 3.08 & 11.27 & $8.46(9.83)$ & $20.56(25.85)$ & $* * *$ \\
\hline 7.Conducta antisocial & $23.18(28.75)$ & 1.93 & 3.88 & 11.41(15.6) & $35.07(33.98)$ & $* * *$ \\
\hline Vandalismo & $6.06(5.67)$ & 1.24 & 1.34 & $4.02(4.14)$ & $8.09(6.31)$ & $* * *$ \\
\hline Hurtos & $7.57(12.55)$ & 2.15 & 4.51 & $2.51(6)$ & $12.51(15.16)$ & $* * *$ \\
\hline Agresiones & $9.56(13.10)$ & 1.97 & 3.81 & $4.88(8.55)$ & $14.47(16.71)$ & $* * *$ \\
\hline
\end{tabular}

Las tasas de asimetría y curtosis se consideraron entre óptimas $( \pm 1)$ y aceptables $( \pm 2)$ (George \& Mallery, 2001), excepto para las variables motivación delictiva y conducta antisocial, que por su propia naturaleza de riesgo tienden a tener una distribución más asimétrica, de menor concentración de casos, hacia a el extremo derecho, indicativo de un mayor riesgo. Se realizó una inspección gráfica de los residuos para descartar problemas de heterocedasticidad. Los niveles de tolerancia, el factor de inflación de varianza (VIF) y el índice de condición se analizaron indicando la ausencia de multicolinealidad entre las variables (tolerancia > .10, VIF <10 e índices de condición <30). Finalmente, se detectaron siete casos atípicos univariados (puntajes $Z$ superiores a \pm 3.29 ) y cinco atípicos multivariados, a través de la distancia de Mahalanobis $(p<.001)$. De ellos, cuatro fueron atípicos univariados y multivariados en simultáneo. No hubo diferencias sustantivas en los resultados de las pruebas de modelos con y sin valores atípicos, por lo que los resultados se informan incluyendo estos casos. En todas las variables analizadas los varones presentaron puntuaciones significativamente más elevadas que las mujeres, a excepción de las variables pobre parentalidad materna y oportunidad delictiva donde, pese a que las puntuaciones de los varones fueron superiores, las diferencias no alcanzaron el nivel de significación.

Revista Española de Investigación Criminológica

Artículo 6, Volumen 19 (2021)

https://doi.org/10.46381/reic.v19i1.479

www.criminologia.net

ISSN: 1696-9219 
Los indicadores del ajuste del modelo de medida para la muestra total revelaron un ajuste óptimo $\left(\chi^{2}=214.15 ; g l=104 ; p<.001 ; C M I N / g l=2.06, C F \mathrm{I}=.98, G F I=.94, R M S E A=\right.$ .05 y $S R M R=.03)$. Todos los parámetros fueron significativos a un nivel de $p<.001$, indicando una buena representación de las variables latentes por parte de sus indicadores observables (figura 2). Las correlaciones entre las variables latentes también resultaron significativas a un nivel de $p<.001$, con excepción de las correlaciones entre bajo autocontrol y oportunidad $(p<.05)$, entre bajo autocontrol y pobre parentalidad materna $(p<.05)$, entre pobre parentalidad materna y pares antisociales $(p<.01)$, y entre pobre parentalidad materna y oportunidad $(p<.01)$.

\section{Figura 2}

Modelo de medida

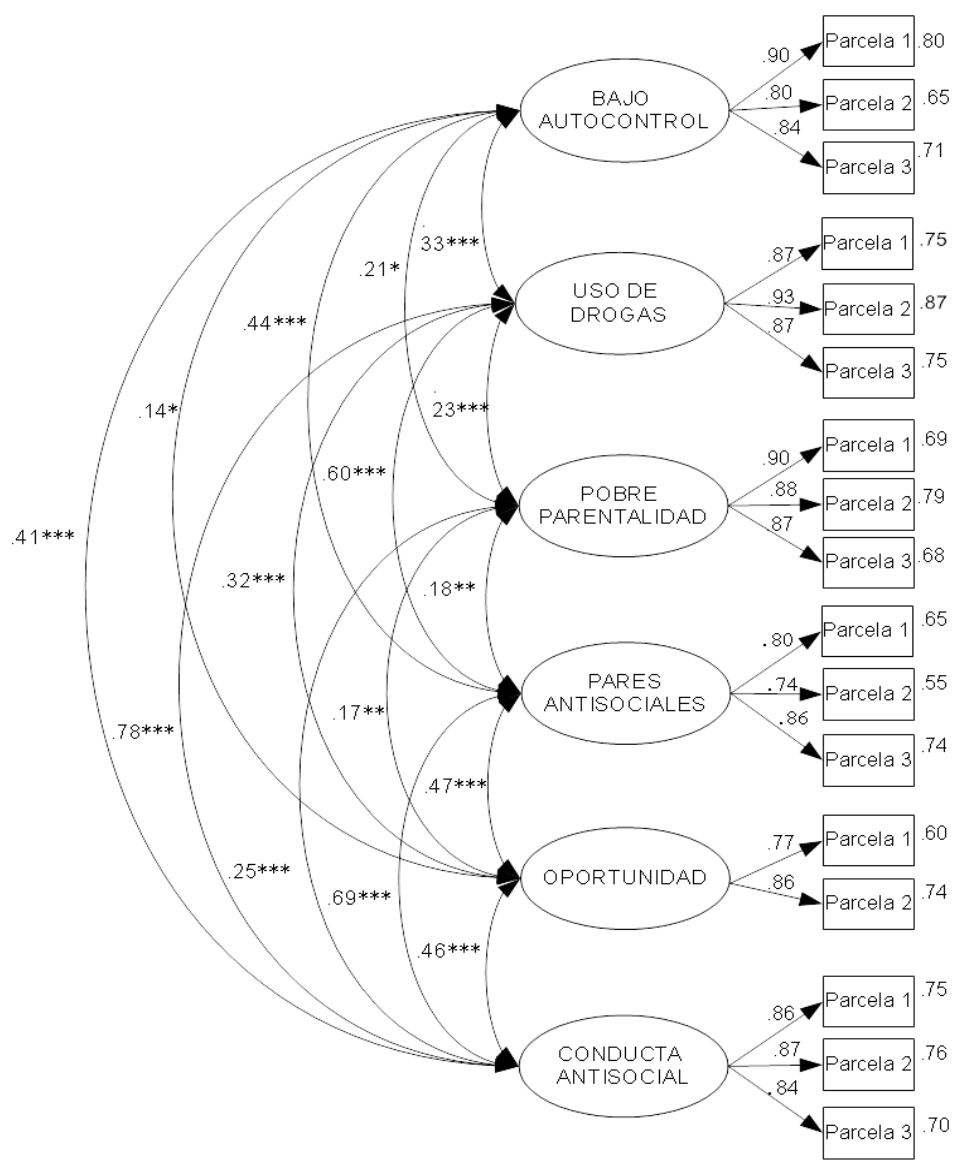

Nota. $* p<.05 ; * * p<.01 ; * * * p<.001$

Revista Española de Investigación Criminológica

Artículo 6, Volumen 19 (2021)

https://doi.org/10.46381/reic.v19i1.479

www.criminologia.net

ISSN: 1696-9219 


\subsection{Análisis de invarianza estructural}

Los valores de ajuste para los cuatro modelos fueron de aceptables a óptimos, con excepción del índice GFI que solo resultó aceptable en el caso del modelo sin restricciones (Tabla 2). Sin embargo, el cambio en $\chi^{2}$ respecto al modelo sin restricciones fue significativo para todos los modelos con restricciones. Esto sugiere que la variable sexo modera tanto el efecto de unas variables sobre otras, como las covarianzas y el porcentaje explicado en las varianzas de las variables endógenas.

\section{Tabla 2}

Índices de ajuste de los modelos con y sin restricciones y diferencia en $\chi^{2}$

\begin{tabular}{llllllll}
\hline & $\chi^{2}$ & $g l$ & $\chi^{2} / g l$ & GFI & CFI & RMSEA & Dif. $\chi^{2}$ \\
\hline ML & $417.05^{* * * *}$ & 244 & 1.71 & .90 & .97 & .04 & \\
MI1 (path) & $480.61^{\text {**** }}$ & 252 & 1.91 & .89 & .95 & .05 & $63.56^{* * *}$ \\
MI2 (cov) & $463.57^{* * * *}$ & 250 & 1.85 & .89 & .96 & .05 & $46.52^{* * * *}$ \\
MI3 (resid) & $486.40^{\text {**** }}$ & 247 & 1.97 & .88 & .95 & .05 & $69.35^{* * *}$ \\
\hline
\end{tabular}

Nota: ${ }^{* * *} \mathrm{p}<.001$. Las diferencias en $\chi^{2}$ son respecto al modelo sin restricciones

La figura 3 muestra los coeficientes para cada grupo. Para determinar en qué parámetros específicos se diferenciaban los grupos se llevaron a cabo tres análisis:

a) Determinación de diferencias en coeficientes path: se plantearon ocho modelos restrictivos donde en cada uno de ellos se determinó la igualdad de un path (por ejemplo, MP1 igualdad en Vía A, MP2 igualdad en Vía B, y así sucesivamente).

b) Determinación de diferencias en covarianzas: se plantearon seis modelos restrictivos donde en cada uno de ellos se especificó la igualdad de una covarianza (por ejemplo, MC1 igualdad en covarianza entre bajo autocontrol y uso de drogas).

c) Determinación de diferencias en residuales: se plantearon tres modelos restrictivos donde en cada uno de ellos se determinó la igualdad de residuales de una variable endógena (por ejemplo, MR1 igualdad en residuales de motivación delictiva, MR2 igualdad en residuales de oportunidad). 


\section{Figura 31}

Covarianzas, coeficientes path y $R^{2}$ del modelo TRD según el sexo

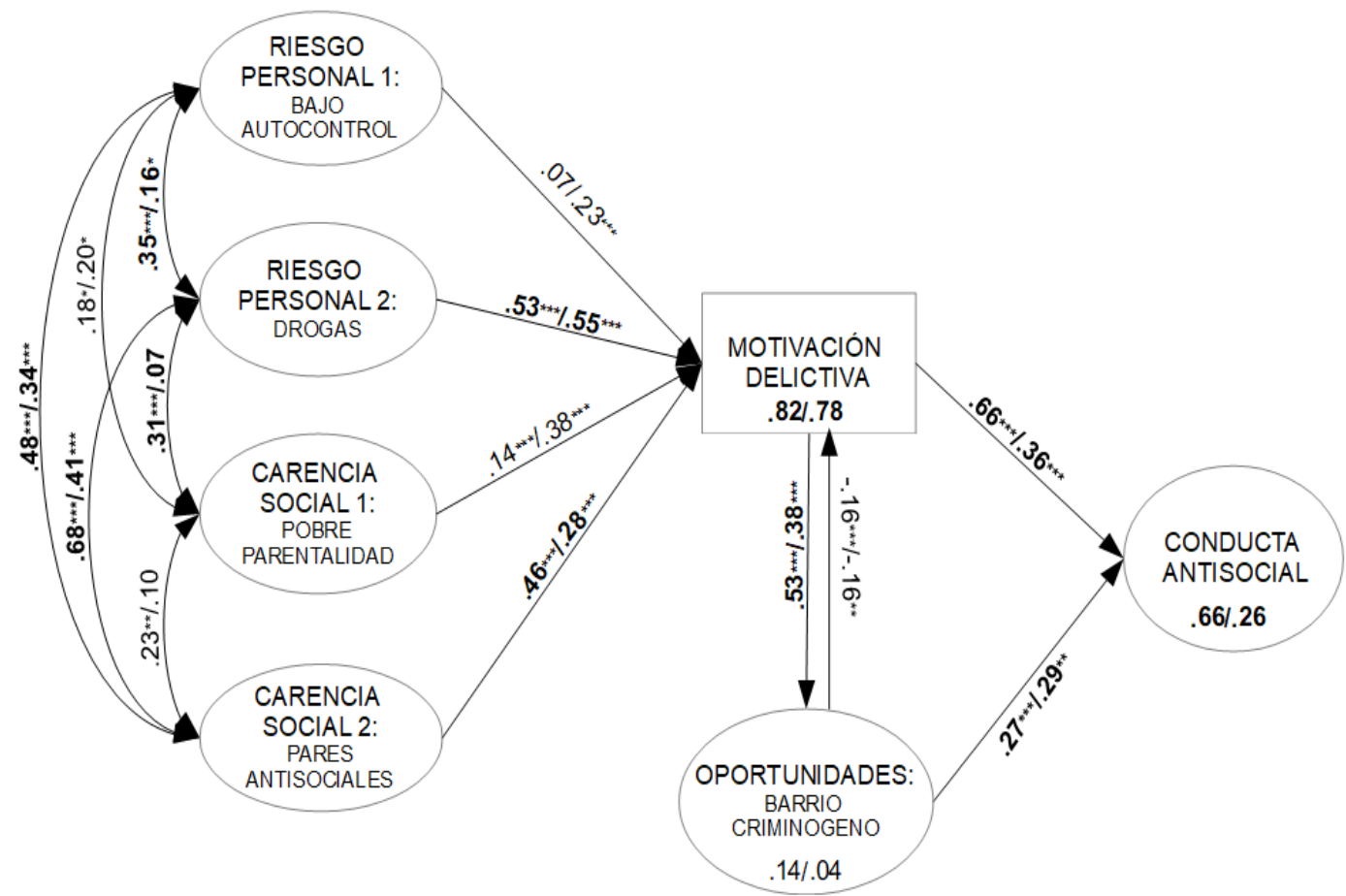

Nota. A la izquierda de la barra (/), coeficientes de varones; a la derecha, coeficientes de mujeres. En negrita, los coeficientes significativamente diferentes entre los grupos.

\section{Diferencias en los coeficientes path entre mujeres y varones}

Los resultados indicaron que 5 de los 8 modelos testeados tuvieron $\chi^{2}$ significativamente inferiores al modelo sin restricciones (Tabla 3). Esto muestra que cinco paths funcionaron de forma diferente para mujeres y varones. Así, mientras el uso de drogas tuvo un efecto ligeramente superior sobre la motivación delictiva en las mujeres, lo inverso ocurrió con los pares antisociales, cuyo efecto fue mayor en los varones. Los efectos de la motivación delictiva sobre la oportunidad y sobre la conducta antisocial fueron mayores para los varones. En un sentido opuesto, el efecto de la oportunidad sobre la conducta antisocial fue superior en las mujeres en comparación con los varones (Figura 3). Si bien la influencia del bajo autocontrol y la pobre parentalidad sobre la motivación delictiva fue superior en las mujeres, estas diferencias no alcanzaron el nivel de significación estadística de $p<.05$.

Revista Española de Investigación Criminológica

Artículo 6, Volumen 19 (2021)

https://doi.org/10.46381/reic.v19i1.479

www.criminologia.net

ISSN: 1696-9219 
Bobbio, Arbach \& Redondo

\section{Tabla 31}

Índices de ajuste de los modelos con y sin restricciones en los path: diferencia en $\chi^{2}$

\begin{tabular}{llllllll}
\hline & $\chi^{2}$ & $g l$ & $\chi^{2} / g l$ & GFI & CFI & RMSEA & Dif. $\chi^{2}$ \\
\hline ML & $417.05^{* * *}$ & 244 & 1.71 & .899 & .965 & .04 & \\
MP1: BAC $\rightarrow$ MD & $417.65^{* * *}$ & 245 & 1.71 & .899 & .965 & .04 & .59 \\
MP2: DR $\rightarrow$ MD & $421.81^{* * *}$ & 245 & 1.72 & .899 & .964 & .04 & $4.75^{*}$ \\
MP3: PPM $\rightarrow$ MD & $417.61^{* * *}$ & 245 & 1.71 & .899 & .965 & .04 & .56 \\
MP4: PA $\rightarrow$ MD & $430.19^{* * *}$ & 245 & 1.76 & .898 & .962 & .04 & $13.14^{* * *}$ \\
MP5: OD $\rightarrow$ MD & $420.79^{* * *}$ & 245 & 1.72 & .899 & .964 & .04 & 3.74 \\
MP6: MD $\rightarrow$ OD & $421.32^{* * *}$ & 245 & 1.72 & .898 & .964 & .04 & $4.27^{*}$ \\
MP7: MD $\rightarrow$ CA & $423.92^{* * *}$ & 245 & 1.73 & .898 & .964 & .04 & $6.87^{* *}$ \\
MP8: OD $\rightarrow$ CA & $422.05^{* * *}$ & 245 & 1.72 & .898 & .964 & .04 & $4.99^{*}$ \\
\hline
\end{tabular}

Nota . $\mathrm{BAC}=$ bajo autocontrol; $\mathrm{DR}=$ drogas; $\mathrm{PPM}=$ pobre parentalidad materna; $\mathrm{PA}=$ pares antisociales; $\mathrm{MD}=$ motivación delictiva; $\mathrm{OD}=$ oportunidad delictiva; $\mathrm{CA}=$ conducta antisocial.

\section{Diferencias en las covarianzas entre adolescentes de ambos sexos}

De las covarianzas del modelo, cuatro resultaron significativamente diferentes según el sexo: 1) drogas y bajo autocontrol, 2) drogas y pobre parentalidad, 3) drogas y pares, 4) bajo autocontrol y pares. En todos los casos las covarianzas fueron más robustas para los varones, es decir, estas variables estuvieron más fuertemente relacionadas entre sí en los varones que en las mujeres (Tabla 4). 
Bobbio, Arbach \& Redondo

\section{Tabla 4}

Índices de ajuste de los modelos con y sin restricciones en las covarianzas: diferencia en $\chi^{2}$

\begin{tabular}{llllllll}
\hline & $\chi^{2}$ & $g l$ & $\chi^{2} / g l$ & GFI & CFI & RMSEA & Dif. $\chi^{2}$ \\
\hline ML & $417.05^{* * *}$ & 244 & 1.71 & .899 & .97 & .04 & \\
MC1: PA y PPM & $419.31^{* * *}$ & 245 & 1.71 & .899 & .96 & .04 & 2.26 \\
MC2: PA y DR & $458.32^{* * *}$ & 245 & 1.87 & .889 & .96 & .05 & $41.26^{* * *}$ \\
MC3: PA y BAC & $427.49^{* * *}$ & 245 & 1.75 & .897 & .96 & .04 & $10.43^{* *}$ \\
MC4: PPM y DR & $424.60^{* * *}$ & 245 & 1.73 & .898 & .96 & .04 & $7.54^{* *}$ \\
MC5: PPM y BAC & $417.14^{* * *}$ & 245 & 1.70 & .899 & .97 & .04 & .09 \\
MC6: DR y BAC & $427.71^{* * *}$ & 245 & 1.75 & .896 & .96 & .04 & $10,65^{* *}$ \\
\hline
\end{tabular}

Nota. $* * * p<.001 ; * * p<.01$.

$\mathrm{BAC}=$ bajo autocontrol; $\mathrm{DR}=$ drogas $; \mathrm{PPM}=$ pobre parentalidad materna; $\mathrm{PA}=$ pares antisociales.

\section{Diferencias en los residuales}

Tanto la motivación delictiva como la conducta antisocial fueron significativamente mejor explicadas por el modelo en los varones que en las mujeres (Tabla 5), con tamaños del efecto grandes para ambos grupos $\left(R^{2}=.78, f^{2}=1.88\right.$ mujeres vs. $R^{2}=.82 ; f^{2}=2.13$ varones en motivación delictiva; $R^{2}=.26, f^{2}=0.59$ mujeres vs. $R^{2}=.66 ; f^{2}=1.39$ varones en conducta antisocial). Sin embargo, estas diferencias fueron más sustanciales en el caso de la conducta antisocial que en el de la motivación delictiva. Finalmente, en relación con la variable oportunidad, aunque evidenció una mayor varianza explicada en los varones que en las chicas $\left(R^{2}=.04_{s} f^{2}=0.20\right.$ mujeres vs. $R^{2}=.14 ; f^{2}=0.40$ varones $)$, las diferencias entre ambos grupos no fueron significativas. 
Bobbio, Arbach \& Redondo

Tabla 52

Índices de ajuste de los modelos con y sin restricciones en los residuales: diferencia en $\chi^{2}$

\begin{tabular}{llllllll}
\hline & $\chi^{2}$ & $g l$ & $\chi^{2} / g l$ & $G F I$ & $C F I$ & $R M S E A$ & Dif. $\chi^{2}$ \\
\hline ML & $417.05^{* * *}$ & 244 & 1.71 & .899 & .97 & .04 & \\
MR1: MD & $469.26^{* * *}$ & 245 & 1.92 & .886 & .95 & .05 & $52.21^{* * *}$ \\
MR2: OD & $417.63^{* * *}$ & 245 & 1.71 & .899 & .97 & .04 & .57 \\
MR3: CA & $435.19^{* * *}$ & 245 & 1.78 & .893 & .96 & .04 & $18.14^{* * *}$ \\
\hline
\end{tabular}

Nota. $* * * p<.001 ; * * p<.01$.

$\mathrm{MD}=$ motivación delictiva; $\mathrm{OD}=$ oportunidad delictiva; $\mathrm{CA}=$ conducta antisocial.

\section{Discusión}

El objetivo general de este estudio ha sido contrastar empíricamente la estructura teórica del Modelo del Triple Riesgo Delictivo (TRD; Redondo, 2008, 2015) a partir de una muestra de adolescentes argentinos de ambos sexos. Los resultados obtenidos, mediante un análisis multigrupo, indican que el Modelo TRD funciona adecuadamente para mujeres y varones; es decir, que las variables analizadas y sus relaciones, que se derivaron del Modelo TRD y se pusieron a prueba en este trabajo, contribuyen a anticipar y explicar la conducta antisocial observada en los grupos de varones y mujeres evaluados. Con carácter general, los factores consumo de sustancias, pares antisociales y prácticas parentales (inapropiadas) serían predictores robustos de comportamiento antisocial en la adolescencia, tanto para el caso de las chicas como de los chicos, tal como se ha documentado en estudios previos (Burt et al., 2019; Cutrín et al., 2017; Trudeau et al., 2012; Weerman \& Hoeve, 2012). Este resultado sostendría la idea de que los mecanismos causales del comportamiento antisocial podrían ser esencialmente comunes a ambos sexos (Cutrín et al., 2017; Javdani et al., 2011; Slawinski et al., 2019; Trudeau et al., 2012; Weerman \& Hoeve, 2012). No obstante, las magnitudes de las relaciones e influencias recíprocas observadas entre variables muestran algunas diferencias en función del sexo de los participantes. Por ejemplo, mientras que el consumo de sustancias se asoció algo más a la motivación delictiva de las chicas, el hecho de tener pares o amigos antisociales tuvo un mayor impacto en la motivación de los varones.

Revista Española de Investigación Criminológica

Artículo 6, Volumen 19 (2021)

https://doi.org/10.46381/reic.v19i1.479

www.criminologia.net

ISSN: 1696-9219 
Aunque fue mayor el peso relativo del consumo de sustancias en el comportamiento antisocial de las mujeres, en ellas esta variable se relacionó de manera más débil con el resto de los factores de riesgo. Esto podría explicarse por la mayor dispersión de esta variable en los varones lo que, a su vez, implica una mejor representación de todos sus niveles en este grupo. En consecuencia, las correlaciones del consumo de sustancias y otras variables tienden a ser menores en las mujeres dado ellas constituyen un grupo más homogéneo en cuanto a la distribución de frecuencias de esta variable (Bologna, 2020). Desde un punto de vista teórico, las desigualdades en los roles sociales que históricamente se han asignado a cada género (Connell \& Messerschmidt, 2005; Levant et al., 2009) podrían explicar, al menos en parte, la menor heterogeneidad y mayor concentración de las mujeres en niveles bajos de éste y otros factores de riesgo. De acuerdo con esta perspectiva, el consumo de sustancias sería socialmente menos aceptado en ellas; esto explicaría las puntaciones promedio significativamente más bajas en esta variable, en comparación con los chicos. Así, cuando el consumo está efectivamente presente en las mujeres puede constituirse en un factor de riesgo de mayor influencia que en los varones, para los cuales el consumo de drogas es algo más frecuente.

Sin embargo, la definición del consumo de sustancias como un predictor de riesgo personal podría resultar problemática en el contexto del Modelo TRD. El consumo de sustancias admite en la formulación de dicho modelo teórico una doble valencia. Por un lado puede ser considerado, en efecto, un factor de riesgo de naturaleza personal, en la medida en que la experiencia reiterada de consumo podría generar una cierta adicción o propensión a consumir, susceptible de favorecer conductas delictivas como robos y agresiones (a menudo, delitos funcionales para la obtención de sustancias tóxicas; Redondo \& Garrido, 2013). Pero, por otro, el consumo de sustancias también podría ser catalogado como un comportamiento antisocial en sí, análogo a otras conductas infractoras. Desde este planteamiento, el consumo no debería emplearse como factor de riesgo de la conducta delictiva, ya que en el Modelo TRD se aduce que unas conductas infractoras no deberían ser utilizadas como predictores (o variables independientes) de otras: todas ellas serían en realidad indicadores diferentes del comportamiento delictivo (es decir, de la variable dependiente). 
Esta ambivalencia posible del consumo de sustancias, como predictor de riesgo y como conducta antisocial, constituye un dilema de imposible solución en términos abstractos; más bien dependerá de la concepción de las variables de cada estudio. Para el caso de la muestra juvenil aquí evaluada, se optó por no conceptuar el consumo (generalmente, de sustancias de amplia utilización juvenil) como un comportamiento delictivo en sí, ya que no es una conducta directa de agresión o engaño para dañar a otros o sus propiedades, que es como se concibe la conducta delictiva en el Modelo TRD (Redondo, 2008, 2015). De este modo, el consumo de sustancias tóxicas se definió aquí como un posible factor de riesgo que, dependiendo de su intensidad, podría asociarse a infracciones más graves como vandalismo, hurtos o agresiones.

Respecto a la influencia antisocial de los pares o amigos en función del sexo de los sujetos, existe evidencia científica previa coherente con lo observado en este estudio: los jóvenes varones muestran una mayor influencia criminógena de sus pares antisociales que las chicas (Piquero et al., 2005; Trudeau et al., 2012). Esto podría relacionarse también con el hecho de que los niños podrían experimentar a menudo una menor supervisión paterna que las niñas, viéndose por ello más expuestos al influjo de otros posibles riesgos (Bobbio et al., 2016; Richards et al., 2004; Weerman \& Hoeve, 2012). Asimismo, los varones generalmente informan de que pasan más tiempo con sus amigos, a menudo en la calle en ausencia de supervisión adulta (Weerman et al., 2016). Ambos aspectos constituyen, según se vio al principio, elementos de frecuente diferenciación entre varones y mujeres realzados en el Modelo TRD (Redondo, 2015): la menor supervisión paterna como carencia en apoyo prosocial; el pasar más tiempo con los amigos en la calle como indicador de oportunidad delictiva.

Todos los predictores aquí analizados se asociaron significativamente con la motivación delictiva de las mujeres y todos, excepto el bajo autocontrol, lo hicieron también con la motivación delictiva de los varones. Este último resultado es contradictorio con lo encontrado en múltiples estudios a este respecto, en los que el bajo autocontrol ha mostrado una asociación significativa general con la conducta delictiva de los varones (véase, por ejemplo, el meta-análisis de Ridder et al., 2012). Este resultado atípico podría deberse a que,

Revista Española de Investigación Criminológica

Artículo 6, Volumen 19 (2021)

https://doi.org/10.46381/reic.v19i1.479

www.criminologia.net

ISSN: 1696-9219 
mientras que en el meta- análisis aludido no se contempló la posible influencia de otros posibles predictores de riesgo, en combinación con el autocontrol, aquí sí que se hizo. En nuestro estudio, la sola influencia de los pares antisociales y del consumo de sustancias parece haber sido suficiente para incrementar la motivación delictiva de los varones, lo que probablemente habría decrecido en los análisis el peso estadístico del autocontrol. Algunas investigaciones con adolescentes latinoamericanos (Chouhy et al., 2016) y norteamericanos (Koon-Magnin et al., 2016) también han obtenido, en línea con nuestro resultado, que el bajo autocontrol no aparecía tan asociado a la conducta delictiva de los varones como sí lo estaban otras variables personales y sociales. Valoramos que el menor efecto del autocontrol sobre la motivación antisocial, en contraste con el peso de otros factores, no menoscaba la conclusión general del estudio. En contraposición a la consideración del autocontrol como el factor explicativo central del delito (por ej., en la Teoría General del Delito, Gottfredson \& Hirschi, 1990), el modelo TRD sugiere una explicación más diversificada y dinámica de la conducta delictiva, en la que el autocontrol puede ser una variable relevante de entre otras posibles. Según ello, en ausencia de otros factores de riesgo (como aquí sucede en parte para el caso de las chicas), los niveles bajos o muy bajos de autocontrol pueden adquirir una mayor relevancia. En función de esto cobra pleno sentido su inclusión en los instrumentos de valoración del riesgo de violencia, como el Structured Assessment of Violence Risk in Youth (SAVRY; Borum et al., 2002).

Además, de manera general, las mujeres suelen experimentar estructuralmente un mayor control en diferentes ámbitos de la vida, a la vez que determinados comportamientos infractores o de riesgo (conducta violenta, consumo de drogas, permanencia prolongada en la calle...) son menos tolerados en las chicas que en los varones (Gottfredson \& Hirschi, 1990). El efecto combinado de ambas experiencias vitales podría contribuir a la adquisición por las chicas de mayores niveles de autocontrol; y determinar, en consecuencia, que justamente la ausencia de dicho autocontrol pueda jugar un rol más destacado en el origen de su posible motivación delictiva (al igual que lo sucedido con el consumo de sustancias), según lo hallado en este trabajo y en estudios anteriores (Perrone et al., 2004). 
Por otra parte, el constructo motivación delictiva tuvo aquí un mayor peso explicativo, sobre la conducta antisocial y las oportunidades, en los chicos que en las chicas. En línea con esto, el porcentaje de varianza explicada de motivación delictiva y de conducta antisocial fue superior en los varones. Es decir, aunque las variables contempladas en este estudio han mostrado ser globalmente útiles para explicar la motivación delictiva y el comportamiento infractor, con tamaños del efecto altos, tanto de varones como de mujeres, han resultado más útiles en el caso de los varones. Un estudio latinoamericano anterior, que contrastó un modelo compuesto por variables predictoras similares a las aquí utilizadas (Rodríguez et al., 2012), también halló mayor poder explicativo para los varones.

Es posible que otras variables predictoras o moduladoras, no incluidas ni en este trabajo ni en el de Rodríguez et al (2012), pudieran contribuir más sólidamente a la explicación de la motivación delictiva de las chicas y, también, de su comportamiento antisocial. Entre ellas, determinadas problemáticas psicopatológicas y de salud mental (Javdani \& Allen, 2014; Moffitt et al., 2001; Zahn et al., 2010) o posibles experiencias previas de victimización (Loinaz \& Andrés, 2017). Tal vez la consideración de estas variables y otras análogas en futuras investigaciones podría ayudar a comprender mejor la motivación delictiva de las mujeres y su influencia sobre el riesgo de conducta antisocial, así como a favorecer mejores intervenciones preventivas y de tratamiento con ellas.

El Modelo TRD constituye una meta- teoría integradora de la delincuencia, susceptible de acoger (a partir de la convergencia de riesgos personales, sociales y ambientales) diversos mecanismos etiológicos específicos, como los identificados por las teorías clásicas del delito (aprendizaje, desvinculación social, tensión, etc.). Es decir, propone que, aunque existen unas fuentes generales de influencia criminógena, los riesgos concretos pueden combinarse y expresarse de manera particular en diferentes grupos e individuos. De ahí que, aunque las prácticas parentales inadecuadas, la asociación con amigos delincuentes, el consumo de sustancias tóxicas y las oportunidades delictivas son predictores frecuentes de la conducta antisocial, no necesariamente estarán siempre presentes en todos los jóvenes que cometen delitos ni se combinarán en ellos de igual forma. 
En este estudio, una proporción relevante de la varianza de la conducta antisocial de los jóvenes permaneció inexplicada. Este resultado podría evocar, en coherencia con lo previsto en el Modelo TRD, la posible existencia de otros factores de influencia sobre el comportamiento antisocial, que aquí no se han analizado. Por ejemplo, para el caso de los varones, elementos relacionados con sus características neuroendocrinas (asociadas al sexo biológico), sus creencias antisociales y justificadoras del delito (condicionadas por diferencias culturales y de género), el mayor tiempo que pasan en la calle con sus amigos, podrían haber confluido y, en interacción con los factores analizados, haber incrementado su motivación delictiva por encima de la de las chicas. En todo caso, los datos no permiten afirmarlo con seguridad, sino meramente especular acerca de que otras influencias criminógenas no controladas podrían estar estimulando el mayor riesgo delictivo mostrado aquí por los varones.

Los resultados aquí obtenidos difícilmente pueden relacionarse con los principios más globales del Modelo TRD, como los de convergencia de riesgos (a más riesgos presentes, mayor probabilidad delictiva) y potenciación recíproca entre riesgos. El Modelo TRD sugiere, como se vio, que en general es esperable una mayor convergencia y potenciación de riesgos en los varones que en las chicas, de ahí la mayor prevalencia delictiva general de aquellos (Redondo, 2015). Sin embargo, en este estudio el número de factores analizados por cada fuente de riesgo se limitó, por razones operativas, a un máximo de dos. A partir de ello, difícilmente pueden extraerse conclusiones fidedignas sobre los principios generales de convergencia y potenciación de riesgos.

Por último, los resultados de este trabajo también sugieren que algunas variables sensibles al género deberían considerarse en los análisis futuros, con la finalidad de mejorar la evaluación de posibles factores de riesgo diferenciales en mujeres y varones. Estudios previos han evidenciado la capacidad limitada de los vigentes instrumentos de evaluación de riesgo, generalmente diseñados a partir de muestras de varones, para la predicción del comportamiento antisocial y violento de las mujeres; y la necesidad de prestar mayor atención, para el caso de las mujeres, a factores de naturaleza clínica, como necesidades de 
salud mental, comportamientos autodestructivos y experiencias de previa victimización (de Vogel et al., 2019).

\section{Implicaciones}

Existen investigaciones en el contexto latinoamericano que han estudiado la asociación de algunos de los predictores aquí analizados con la conducta antisocial de los jóvenes (Arbach, 2016; Cosacov \& Croccia, 2007; Picasso \& Crucella, 2018). La novedad de este trabajo reside en su intento de contrastar, a partir de una muestra de jóvenes en Argentina, una teoría explicativa de la conducta antisocial reciente pero que está suscitando un interés creciente en investigadores e instituciones de justicia (Bobbio et al., 2020; Direcció General d'Infància Joventut i Famílies, 2020a, 2020b, 2020c; Direcció General de Serveis Penitenciaris, 2011). Sin embargo, todavía son escasos los testeos empíricos destinados a evaluar los principales postulados del Modelo TRD (Albert Bau, 2010; González García, 2015; Martín et al., 2015; Pérez Ramírez, 2012).

Por otro lado, el análisis de las posibles diferencias en los mecanismos explicativos de la conducta delictiva de mujeres y varones es un reto de investigación imprescindible, aunque hasta ahora muy poco atendido, particularmente en Latinoamérica. De ahí que este trabajo haya tenido como una de sus principales fortalezas el análisis del comportamiento infractor de jóvenes varones y mujeres. En dirección al logro de estas dos finalidades, se ha empleado una metodología de ecuaciones estructurales (SEM), una de cuyas principales utilidades es el contraste de modelos teóricos.

Desde una perspectiva sustantiva, los resultados obtenidos apoyan la estructura general del Modelo TRD, en coherencia con lo hallado en investigaciones previas (Albert Bau, 2010; González García, 2015; Martín et al., 2015; Pérez Ramírez, 2012). Desde un punto de vista práctico, confiamos que este estudio contribuya a dotar a los profesionales de las instituciones de justicia de unos marcos conceptuales más sólidos y contrastados sobre los que fundamentar sus evaluaciones con adolescentes, varones y mujeres, que han cometido delitos. Los hallazgos realizados podrían resultar útiles, tanto en términos científicos como aplicados, en la medida en que un número limitado de predictores ha permitido explicar un

Revista Española de Investigación Criminológica 
porcentaje relevante de la varianza de la conducta delictiva de los adolescentes. Además, el análisis de los factores de riesgo específicos y de cómo estos interactúan entre sí, tomando como referencia la perspectiva integradora del Modelo TRD, podría ayudar a comprender mejor cómo los riesgos operan en individuos y grupos específicos, como adolescentes mujeres y varones. Y contribuir, a la postre, a mejorar la gestión del riesgo delictivo y la atención a las necesidades de intervención más relevantes en cada caso. Así creemos que debería ser también en el contexto de la delincuencia juvenil de la provincia de Córdoba, sede de la muestra de este estudio, en donde la población adolescente institucionalizada por delitos registra una de las tasas más altas de Argentina (UNICEF \& SeNAF, 2015). Trabajar eficientemente con ese elevado volumen de adolescentes, en un contexto en el cual los recursos precisamente no abundan, requeriría la mayor optimización del tiempo y el uso de estrategias de evaluación y gestión del riesgo (Heilbrun et al., 2009). A pesar de las particularidades políticas, sociales y económicas de América Latina, aquí se ha puesto de relieve que las teorías que son de utilidad en otras regiones del mundo también podrían serlo para comprender y prevenir más eficazmente el comportamiento antisocial y delictivo de los jóvenes de estas latitudes (Bobbio et al., 2018).

\section{Limitaciones}

A pesar de las aportaciones referidas, este trabajo no está exhento de algunas limitaciones significativas. En primer lugar, el diseño transversal aquí utilizado no permite, como es obvio, establecer relaciones de temporalidad-causalidad entre las variables predictoras y las variables criterio evaluadas. Tales relaciones solo podrían sugerirse a partir de datos delictivos de cariz longitudinal, no disponibles por ahora ni en Argentina ni en general en Latinoamérica. En segundo lugar, aunque la muestra de jóvenes no infractores incluyó tanto varones como mujeres, no pudo contarse con una muestra específica de chicas en conflicto con la ley debido a que no se pudo acceder a esa población. A pesar de ello, no creemos que la inclusión de chicas infractoras hubiese alterado sustancialmente los resultados globales del estudio, dada la baja proporción de mujeres en el conjunto de los adolescentes que cometen delitos.

Revista Española de Investigación Criminológica

Artículo 6, Volumen 19 (2021)

https://doi.org/10.46381/reic.v19i1.479

www.criminologia.net

ISSN: 1696-9219 
La última limitación relevante que queremos destacar es que no se controló la posible deseabilidad social de los sujetos, por lo que no puede descartarse que esta haya producido algunos sesgos en los datos. Pese a todo, los resultados obtenidos han sido afines a los encontrados en poblaciones similares empleando los mismos intrumentos de medida (Li \& Vazsonyi, 2019), lo que aminora la duda de un sesgo relevante a este respecto.

\section{Conclusión}

Este estudio ha puesto de relieve que los pares o amigos antisociales, las prácticas parentales inapropiadas y el consumo de sustancias tóxicas constituyen predictores de delincuencia comunes a adolescentes varones y mujeres, por lo que deberían ser considerados universalmente en las evaluaciones e intervenciones desarrolladas con jóvenes infractores de ambos sexos. Sin embargo, para el caso de las mujeres no deberían asumirse sin más los modelos de predicción e intervención diseñados para varones, sino que sería necesario explorar empíricamente la relevancia de otros posibles predictores asociados tanto al sexo como al género. Ello podría facilitar una mejor explicación del comportamiento delictivo de las mujeres y el diseño de intervenciones más adecuadas y eficaces con ellas.

\section{Referencias}

Albert Bau, I. (2010). Estudio de autoinforme sobre factores de riesgo y carrera delictiva en una muestra de delincuentes encarcelados [Tesis de Mestría]. Universidad de Barcelona, España.

American Psychological Association. (2017). Ethical principles of psychologists and code of conduct.

Arbach, K. (2016). Violencia de pareja en jóvenes: factores de riesgo y claves para su prevención. En Informe Técnico Del Proyecto de Investigación Categoría A. Secretaría de Ciencia y Técnica. Univerisdad Nacional de Córdoba.

Bobbio, A. \& Arbach, K. (2020). Validation of the Low Self-Control Scale Spanish Version: a bifactor model approach. Psychiatry, Psychology and Law, 1-17. https://doi.org/10.1080/13218719.2020.1782283

Bobbio, A. Arbach, K. \& Alderete, A. (2016). Evaluación de las prácticas parentales: Análisis psicométrico de la escala Adolescent Family Process. Evaluar, 16(1), 46-65. https://doi.org/https://doi.org/10.35670/1667-4545.v16.n1.15941

Revista Española de Investigación Criminológica

Artículo 6, Volumen 19 (2021)

https://doi.org/10.46381/reic.v19i1.479

www.criminologia.net

ISSN: 1696-9219 
Bobbio, A., Arbach, K. \& Redondo, S. (2020). Juvenile delinquency risk factors: Individual, social, opportunity or all of these together? International Journal of Law, Crime and Justice, 62, 100388. https://doi.org/10.1016/j.ijlcj.2020.100388

Bobbio, A., Arbach, K. \& Vazsonyi, A. T. (2018). Self-Control and Deviance: A Test of the General Theory of Crime in Argentina. Victims \& Offenders, 14(1), 119-142. https://doi.org/10.1080/15564886.2018.1552222

Bologna, E. (2020). Un recorrido por los métodos cuantitativos en Ciencias Sociales a bordo de $R$. https://www.researchgate.net/publication/338584652_Un_Recorrido_por_los_Metodo s_Cuantitativos_en_Ciencias_Sociales_a bordo_de_R

Borum, R., Bartel, P. \& Forth, A. (2002). SAVRY: Manual for the Structured Assessment of Violence Risk in Youth. Florida Mental Health Institute; University of South Florida.

Burt, S. A, Slawinski, B. L., Carsten, E. E., Harden, K. P., Hyde, L. W., \& Klump, K. L. (2019). How should we understand the absence of sex differences in the genetic and environmental origins of antisocial behavior? Psychological Medicine, 49(10), 16001607. https://doi.org/10.1017/s0033291719000771

Centro de Estudios y Proyectos Judiciales. (2017). Adolescentes privados de la libertad en Córdoba Capital por presunta infracción a la Ley Penal. Centro de Estudios y Proyectos Judiciales - Tribunal Superior de Justicia. https://cepj.justiciacordoba.gob.ar/wp-content/uploads/2019/12/2016-InformeAdolescentes-Privados-de-la-Libertad.pdf

Chesney-Lind, M. \& Shelden, R. G. (2014). Girls, delinquency and juvenile justice (4ta ed.). Wiley-Blackwell.

Chouhy, C., Cullen, F. T. \& Unnever, J. D. (2016). Mean streets revisited: Assessing the generality of rival criminological theories. Victims \& Offenders, 11(2), 225-250. https://doi.org/10.1080/15564886.2014.974791

Connell, R. W. \& Messerschmidt, J. W. (2005). Hegemonic masculinity rethinking the $\begin{array}{llll}\text { concept. } \quad \text { Gender } & \text { Society, }\end{array}$ https://doi.org/10.1177/0891243205278639

Cortoni, F., Hanson, R. K. \& Coache, M. È. (2010). The recidivism rates of female sexual offenders are low: A meta-analysis. Sexual Abuse: Journal of Research and Treatment, 22(4), 387-401. https://doi.org/10.1177/1079063210372142

Cosacov, E. \& Croccia, L. (2007). Menores en conflicto con la ley penal. Colección $\begin{array}{llll}\text { Investigaciones } & y & \text { Ensayos, } & \text { 3(2), }\end{array}$ https://biblioteca.cejamericas.org/bitstream/handle/2015/4047/menoresenconflicto.pdf ?sequence $=1 \&$ is Allowed $=\mathrm{y}$

Cutrín, O., Gómez-Fraguela, J. A. \& Sobral, J. (2017). Gender differences in the influence of parenting on youth antisocial behavior through deviant peers. Spanish Journal of Psychology, 1-10. https://doi.org/10.1017/sjp.2017.53

de Vogel, V., Bruggeman, M. \& Lancel, M. (2019). Gender-sensitive violence risk assessment: Predictive validity of six tools in female forensic psychiatric patients. Criminal Justice and Behavior, 46(4), 528-549. https://doi.org/10.1177/0093854818824135

Revista Española de Investigación Criminológica

Artículo 6, Volumen 19 (2021)

https://doi.org/10.46381/reic.v19i1.479

www.criminologia.net

ISSN: 1696-9219 
Direcció General d’Infància Joventut i Famílies. (2020a). Projecte educatiu del Centre Socioeducatiu Es Fusteret. Conselleria d'Afers Socials i Esports, Govern de Les Illes Balears, España.

Direcció General d'Infància Joventut i Famílies. (2020b). Projecte educatiu del Centre Socioeducatiu Es Mussol. Conselleria d'Afers Socials i Esports, Govern de Les Illes Balears, España.

Direcció General d'Infància Joventut i Famílies. (2020c). Projecte educatiu del Centre Socioeducatiu Es Pinaret. Conselleria d'Afers Socials i Esports, Govern de Les Illes Balears, España.

Direcció General de Serveis Penitenciaris. (2011). El Model de Rehabilitació a les presos catalanes. Generalitat de Catalunya. http://www20.gencat.cat/docs/Justicia/Documents/Publicacions/model_rehabilitacio_p resons_catalanes.pdf

Echeburúa, E. \& Redondo, S. (2010). ¿Por qué víctima es femenino y agresor masculino? La violencia contra la pareja y las agresiones sexuales. Ediciones Pirámide.

El País. (2011, marzo 24). Nota de prensa: Dictámenes criminológicos. del Fiscal de Sala Coordinador de Seguridad Vial, Fiscalía General del Estado, Madrid.

Eme, R. (2018). Sex differences in temperament: A partial explanation for the sex difference in the prevalence of serious antisocial behaviors. Aggression and Violent Behavior, 40, 101-107. https://doi.org/10.1016/j.avb.2018.04.005

Fernández-Molina, E. \& Bartolomé, R. (2020). Juvenile crime drop: What is happening with youth in Spain and why? European Journal of Criminology, 17(3), 306-331. https://doi.org/10.1177/1477370818792383

Garrido, S. J., Arbach, K., Cupani, M., Ghio, F. B., Azpilicueta, A. E. \& Moran, V. E. (2019). Propiedades psicométricas de la Escala de Desviación de la Norma en jóvenes. Liberabit: Revista Peruana de Psicología, 25(2), 233-249. https://doi.org/10.24265/liberabit.2019.v25n2.07

George, D. \& Mallery, P. (2001). SPSS for Windows step by step: A simple guide and reference. Allyn and Bacon. https://doi.org/9780335262588

Giddens, A. (2009). Sociology (6ta ed.). Wiley.

González García, A. (2015). El ciberbullying o acoso juvenil a través de Internet un análisis empírico a través del modelo del Triple Riesgo Delictivo (TRD). [Tesis doctoral, Universidad de Barcelona]. http://www.pensamientopenal.com.ar/system/files/2016/09/doctrina44059.pdf

González García, A., \& Campoy Torrente, P. (2018). Ciberacoso y cyberbullying: Diferenciación en función de los precipitadores situacionales. Revista Española de Investigación Criminológica, 16(2018), 1-31. https://doi.org/10.46381/reic.v16i0.149

Gottfredson, M. R. \& Hirschi, T. (1990). A General Theory of Crime. Stanford University Press.

Grasmick, H., Tittle, C., Bursik, R. \& Arneklev, B. (1993). Testing the core empirical implications of Gottfredson and Hirschi's General Theory of Crime. Journal of Research in Crime and Delinquency, 30, 5-29. https://doi.org/10.1177/0022427893030001002

Revista Española de Investigación Criminológica

Artículo 6, Volumen 19 (2021)

https://doi.org/10.46381/reic.v19i1.479

Www.criminologia.net

ISSN: 1696-9219 
Gudjonsson, G. H., Einarsson, E., Bragason, Ó. Ö. \& Sigurdsson, J. F. (2006). Personality predictors of self-reported offending in Icelandic students. Psychology, Crime and Law, 12(4), 383-393. https://doi.org/10.1080/10683160500056929

Hair, J. F., Anderson, R. E., Tatham, R. L. \& Black, W. (2006). Análisis multivariante (6ta ed.). Pearson Education.

Heilbrun, K., Yasuhara, K. \& Shah, J. (2009). Violence risk assessment tools: overview and clinical analysis. En R. K. Otto \& K. S. Douglas (Eds.), Handbook of violence risk assessment (pp. 1-18). Routledge.

IBM Corp. (2012). IBM SPSS AMOS for Windows, Version 21.0 ( $\left.\mathrm{N}^{\mathrm{o}} 21\right)$. IBM Corp.

IBM Corp. (2013). IBM SPSS Statistics for Windows, Version 22.0 ( $\mathrm{N}^{\mathrm{O}} 22$ ). IBM Corp.

Javdani, S. \& Allen, N. E. (2014). An ecological model for intervention forjuvenile justiceinvolved girls: Development and preliminary prospective evaluation. Feminist Criminology, 1-28. https://doi.org/10.1177/1557085114559514

Javdani, S., Sadeh, N. \& Verona, E. (2011). Expanding our lens: Female pathways to antisocial behavior in adolescence and adulthood. Clinical Psychology Review, 31(8), 1324-1348. https://doi.org/10.1016/j.cpr.2011.09.002

Kerig, P. K. (2018). Polyvictimization and girls' involvement in the Juvenile Justice System: Investigating gender-differentiated patterns of risk, recidivism, and resilience. Journal of Interpersonal Violence, 33(5), 789-809. https://doi.org/10.1177/0886260517744843

Kline, R. B. (2011). Principles and practice of structural equation modeling (3rd ed.).

Koon-Magnin, S., Bowers, D., Langhinrichsen-Rohling, J. \& Arata, C. (2016). Social learning, self-control, gender and variety of violent delinquency. Deviant Behavior, 37(7), 824-836. https://doi.org/10.1080/01639625.2016.1147798

LeDoux, J. (1999). El cerebro emocional. Ariel.

Levant, R. F., Hall, R. J., Williams, C. M., \& Hasan, N. T. (2009). Gender Differences in Alexithymia. Psychology of Men and Masculinity, 10(3), 190-203. https://doi.org/10.1037/a0015652

Ley 25326. (2000). Ley 25326/2000, de 04 de octubre, de protección de los datos personales. En Boletín Oficial de la Nación Argentina.

Li, J.-B. \& Vazsonyi, A. T. (2019). The utility of joint use of the Low Self-Control Scale and the Brief Self-Control Scale in explaining adolescent deviance. European Journal of Criminology, 1-20. https://doi.org/10.1177/1477370819845745

Liu, L. \& Miller, S. L. (2020). Protective factors against juvenile delinquency: Exploring gender with a nationally representative sample of youth. Social Science Research, 86(August 2019), 102376. https://doi.org/10.1016/j.ssresearch.2019.102376

Loinaz, I. (2016). Cuando "el" delincuente es "ella": Intervención con mujeres violentas. Anuario de Psicología Jurídica, 26(1), 41-50. https://doi.org/10.1016/j.apj.2016.04.006

Loinaz, I. \& Andrés, A. (2017). Victimización en la pareja como factor de riesgo en mujeres en prisión. Revista Criminalidad, 59(3), 153-162. http://www.scielo.org.co/scielo.php?script=sci_arttext\&pid=S1794$\underline{31082017000300153}$ 
Mak, A., Heaven, P. \& Rummery, A. (2003). The role of group identity and personality domains as indicators of self-reported delinquency. Psychology, Crime \& Law, 9(1), 918. https://doi.org/10.1080/10683160308144

Martín, I., Muñoz, E., Navarro, C., Maldonado, J., Hurtado, M. C., Muñoz, A. \& Navarro, M. (2015). Menores en riesgo: Una explicación de la delincuencia juvenil desde la perspectiva de la teoría del triple riesgo delictivo. En Boletín Criminológico, Art. 3/2015, mayo-junio ( $n^{o}$ 156). Instituto Andaluz Interuniversitario de Criminología.

Moffitt, T. E., Caspi, A., Rutter, M. \& Silva, P. A. (2001). Sex differences in antisocial behaviour: Conduct disorder, delinquency, and violence in the Dunedin longitudinal study. Cambridge University Press.

Pérez Ramírez, M. (2012). Riesgos personales, sociales y ambientales en la explicación del comportamiento antisocial: estudio empírico sobre el Modelo del Triple Riesgo Delictivo [Tesis doctoral]. Universidad de Barcelona.

Perrone, D., Sullivan, C. J., Pratt, T. C. \& Margaryan, S. (2004). Parental efficacy, selfcontrol, and delinquency: A test of a general theory of crime on a nationally representative sample of youth. International journal of offender therapy and comparative criminology, 48(3), 298-312. https://doi.org/10.1177/0306624X03262513

Picasso, S. L. \& Crucella, L. (2018). Características familiares y conducta delictiva: Un estudio cuasi-control con familias de adolescentes en conflicto con la ley penal [Tesis de Grado]. Universidad Nacional de Córdoba.

Piquero, N. L., Cover, A. R., Macdonald, J. M. \& Piquero, A. R. (2005). The influence of delinquent peers on delinquency: Does gender matter? Youth and Society, 36(3), 251275. https://doi.org/10.1177/0044118X04265652

Redondo, S. (2008). Individuos, sociedades y oportunidades en la explicación y prevención del delito: Modelo del Triple Riesgo Delictivo (TRD) [Individuals, societies and opportunities in the explanation and prevention of crime: Triple Criminal Risk Model (TRD)]. Revista Española de Investigación Criminológica, 7(6), 1-53. https://doi.org/10.46381/reic.v6i0.34

Redondo, S. (2010). Inventario de Riesgo Individuales y Sociales (IRIS). Documento no publicado.

Redondo, S. (2015). El origen de los delitos. Tirant Humanidades.

Redondo, S. \& Garrido, V. (2013). Principios de Criminología (4ta ed.). Tirant Lo Blanch.

Redondo, S. \& Martínez, A. (2014). Inventario de Riesgos Individuales y Sociales (IRIS_R): un nuevo instrumento para evaluar factores de riesgo en consonancia con la estructura del Modelo TRD. X Congreso Español de Criminología, 50-51.

Richards, M. H., Miller, B. V., O’Donnell, P. C., Wasserman, M. S. \& Colder, C. (2004). Parental monitoring mediates the effects of age and sex on problem behaviors among African American urban young adolescents. Journal of Youth and Adolescence, 33(3), 221-233. https://doi.org/10.1023/B:JOYO.0000025321.27416.f6

Ridder, D., De, Lensvelt-mulders, G., Finkenauer, C. \& Stok, M. (2012). Taking stock of self-control: A Meta-Analysis of how trait self-control relates to a wide range of behaviors. Personality and Social Psychology Review, 16(1), 76-99. https://doi.org/10.1177/1088868311418749

Revista Española de Investigación Criminológica

Artículo 6, Volumen 19 (2021)

https://doi.org/10.46381/reic.v19i1.479

www.criminologia.net

ISSN: 1696-9219 
Rodríguez, J. A., Mirón, L. \& Rial, A. (2012). Análisis de la relación entre grupo de iguales, vinculación familiar y escolar, autocontrol y conducta antisocial, en una muestra de adolescentes venezolanos. = Analysis of the relationship between peer group, attachment to family and school, self-control. Revista de Psicología Social, 27(1), 2538. https://doi.org/10.1174/021347412798844033

Slawinski, B. L., Klump, K. L. \& Alexandra Burt, S. (2019). No sex differences in the origins of covariation between social and physical aggression. Psychological Medicine, 49(15), 2515-2523. https://doi.org/10.1017/S0033291718003392

Tobeña, A. (2003). Anatomía de la agresividad humana: de la violencia infantil al belicismo. Random House Mondadori, S. A.

Trudeau, L., Mason, W. A., Randall, G. K., Spoth, R. \& Ralston, E. (2012). Effects of parenting and deviant peers on early to mid- adolescent conduct problems. Journal of Abnormal Child Psychology, 40(8), 1249-1264. https://doi.org/10.1007/s10802-0129648-1.Effects

UNICEF \& SeNAF. (2015). Relevamiento Nacional sobre adolescentes en conflicto con la Ley

Penal.

https://www.unicef.org/argentina/spanish/PROTECCION_AdolescConflictoLeyPenal Final.pdf

Vazsonyi, A., Hibbert, J. R. \& Blake Snider, J. (2003). Exotic enterprise no more? Adolescent reports of family and parenting processes from youth in four countries. Journal of Research on Adolescence, 13(2), 129-160. https://doi.org/10.1111/1532-7795.1302001

Vazsonyi, A., Pickering, L., Junger, M. \& Hessing, D. (2001). An empirical test of a general theory of crime: A four-nation comparative study of self-control and the prediction of deviance. Journal of Research in Crime and Delinquency, 38(2), 91-131. https://doi.org/10.1177/0022427801038002001

Vizcaíno Gutiérrez, M. (2010). Mujeres en la criminalidad: más preguntas que respuestas. Rev. crim, 52(1), 309-330. http://www.scielo.org.co/pdf/crim/v52n1/v52n1a07.pdf

Weerman, F. M., Bernasco, W., Bruinsma, G. J. N. \& Pauwels, L. J. R. (2016). Gender differences in delinquency and Situational Action Theory: A partial test. Justice Quarterly, 33(7), 1182-1209. https://doi.org/10.1080/07418825.2015.1064987

Weerman, F. M. \& Hoeve, M. (2012). Peers and delinquency among girls and boys: Are sex differences in delinquency explained by peer factors? European Journal of Criminology, 9(3), 228-244. https://doi.org/10.1177/1477370811435736

Zahn, M. A., Agnew, R., Fishbein, D., Miller, S., Winn, D.-M., Dakoff, G., Kruttschnitt, C., Giordano, P., Gottfredson, D. C., Payne, A. A., Feld, B. C. \& Chesney-Lind, M. (2010). Causes and Correlates of Girls' Delinquency. En Girls Study Group: Understanding and Responding to Girls' Delinquency.

Revista Española de Investigación Criminológica

Artículo 6, Volumen 19 (2021)

https://doi.org/10.46381/reic.v19i1.479

Www.criminologia.net

ISSN: 1696-9219 


\section{Agradecimientos}

Un agradecimiento especial a todos los adolescentes e instituciones que colaboraron con el estudio.

\section{Financiamiento}

Este trabajo fue parcialmente financiado por la Secretaría de Ciencia y Tecnología (SeCyT), Universidad Nacional de Córdoba (Argentina) [resolución n 313/2016].

Antonella Bobbio es becaria postdoctoral del Consejo Nacional de Investigaciones Científicas y Técnicas (CONICET). Profesora de Psicoestadística Descriptiva e Inferencial de la Facultad de Psicología, Universidad Nacional de Córdoba. Miembro del Grupo de Investigación en Violencia del Instituto de Investigaciones Psicológicas (IIPSI). Ha participado en proyectos de investigación y extensión, realizado estancias en diversos grupos de investigación, participado en congresos locales e internacionales y publicado en revistas científicas. Sus principales áreas de interés son la delincuencia juvenil, el contraste empírico de teorías criminológicas, las agresiones sexuales, el abuso sexual infantil y el consumo de material de explotación sexual infantil.

iD

https://orcid.org/0000-0003-4121-9482

Karin Arbach es investigadora Adjunta del Consejo Nacional de Investigaciones Científicas y Técnicas (CONICET). Profesora Titular en Criminología Clínica, Universidad Nacional de Córdoba. Ha trabajado en el diseño, adaptación y validación de instrumentos de valoración del riesgo de violencia de pareja, de violencia general en población psiquiátrico-forense y de riesgos múltiples en contextos correccionales. Ha realizado acciones de vinculación tecnológica en Poderes Judiciales de diferentes provincias. Ha trabajado en servicios sociocomunitarios de España prestando atención psicológica a víctimas de violencia de pareja. Su principal área de expertise es la valoración estructurada del riesgo de violencia mediante técnicas actuariales y de juicio profesional estructurado.

iD

https://orcid.org/0000-0003-1753-4693

Santiago Redondo es catedrático y profesor de Psicología y Criminología de la Universidad de Barcelona. Autor de una teoría integradora de la delincuencia denominada Modelo del Triple Riesgo Delictivo (TRD). Ha publicado numerosos artículos científicos, capítulos y una treintena de libros. Entre ellos, Principios de Criminología (Tirant lo Blanch, 1999, 2001, 2006, 2013), In-tolerancia cero (Sello Editorial, 2009); ¿Por qué víctima es femenino y agresor masculino? (Pirámide, 2010), El origen de los delitos (Tirant lo Blanch, 2015), y Evaluación y tratamiento de delincuentes (Pirámide, 2008, 2017). En 2018 recibió el Premio Nacional de Criminología "Rafael Salillas", que otorga la Sociedad Española de Investigación Criminológica.

https://orcid.org/0000-0002-0955-8436

Revista Española de Investigación Criminológica

Artículo 6, Volumen 19 (2021)

https://doi.org/10.46381/reic.v19i1.479

Www.criminologia.net

ISSN: 1696-9219 